\title{
Hybrid Scaffolds for Tissue Regeneration: Chemotaxis and Physical Confinement as Sources of Biomimesis
}

\author{
Simone Sprio, ${ }^{1}$ Monica Sandri, ${ }^{1}$ Silvia Panseri, ${ }^{1,2}$ Carla Cunha, ${ }^{1,2}$ and Anna Tampieri ${ }^{1}$ \\ ${ }^{1}$ Laboratory of Bioceramics and Bio-Hybrid Composites, Institute of Science and Technology for Ceramics, \\ National Research Council, 48018 Faenza, Italy \\ ${ }^{2}$ Laboratory of Biomechanics and Technology Innovation, Rizzoli Orthopaedic Institute, 40136 Bologna, Italy
}

Correspondence should be addressed to Anna Tampieri, anna.tampieri@istec.cnr.it

Received 7 April 2012; Accepted 21 June 2012

Academic Editor: Leonard Deepak Francis

Copyright (C 2012 Simone Sprio et al. This is an open access article distributed under the Creative Commons Attribution License, which permits unrestricted use, distribution, and reproduction in any medium, provided the original work is properly cited.

\begin{abstract}
Biomineralization is a complex ensemble of concomitant phenomena, driving the development of vertebrate and invertebrate organisms, particularly the formation of human bone tissue. In such a process collagen molecules assemble and organize in a complex 3-D structure and simultaneously mineralize with nearly amorphous apatite nanoparticles, whose heterogeneous nucleation, growth, and specific orientation are mediated by various chemical, physical, morphological, and structural control mechanisms, activated by the organic matrix at different size levels. The present work investigates on in-lab biomineralization processes, performed to synthesize hybrid hydroxyapatite/collagen scaffolds for bone and osteochondral regeneration. The synthesis processes are carried out by soft-chemistry procedures, with the purpose to activate all the different control mechanisms at the basis of new bone formation in vivo, so as to achieve scaffolds with high biomimesis, that is, physical, chemical, morphological, and ultrastructural properties very close to the newly formed human bone. Deep analysis of cell behaviour in contact with such hybrid scaffolds confirms their strong affinity with human bone, which in turn determines high regenerative properties in vivo.
\end{abstract}

\section{Introduction}

Advances in technology demand an ever-increasing degree of control over material structure, properties, and function, and the synthesis of materials with well-defined morphology, structure, and properties is one of the big challenges in materials synthesis today. In this respect, significant steps forward have recently been made in the generation of inorganic/organic hybrid composite following the discovery that many crystals grow via the assembly of macromolecular units and can therefore be used to generate composites with hierarchical and complex structures [1].

In seeking ways to achieve this, nature provides a unique inspiration for the design and synthesis of new materials [2-4]. Indeed, the structure of most animal organisms is characterised by the coexistence of three-dimensional organic matrices and nanostructured, well-ordered inorganic phases, nucleated, and grown on the matrices during a process known as "biomineralization" $[5,6]$, strictly guided by chemical, physical, morphological, and structural controlling mechanisms. Through such processes, natural organisms form highly organized structures with characteristic texture and anisotropy [7-10], devoted to their sustenance and/or physical protection (i.e., the skeleton in mammals, exoskeleton in insects, and shells in molluscs) characterised by high resistance, lightness, and the capacity to continuously adapt to ever-variable external stimuli, and remodel and selfrepair following traumas of moderate entity.

Several control mechanisms regulate the formation and organization of the mineral phase in such organisms: (i) chemical factors, consisting in the precipitation of ions naturally present in the environment, mediated by complex macromolecular organic structures, which act as sites of heterogeneous nucleation and control specific chemical interactions, (ii) spatial factors, consisting in the confinement of the nuclei growth, as well as constraint in their shape and contact with the organic substrate, (iii) structural factors, inducing peculiar crystallographic features driven by the 
interaction between mineral phase and the organic template and (iv) finally, morphologic factors (morphogenesis), where the mineral phase takes a complex architecture on a macroscopic scale, strictly dependent on the combination of the various phenomena above described, which hierarchically occur on different dimensional scales in correspondence with the sites of heterogeneous nucleation. All these control mechanisms concur to the realization of three-dimensional hybrid (organic-inorganic) composites showing superior physicochemical and texturing properties, as well as marked biomimicry and bioactivity. In this respect, the formation of hard tissues in mammals takes place through the assembling of collagen nanofibrils in the extracellular space and the nucleation of the mineral phase, driven by noncollagenous acidic macromolecules [11]. The mineral phase is made of a nearly amorphous calcium phosphate with the structure of hydroxyapatite (HA), containing several ions substituting calcium and phosphate (e.g., $\mathrm{Mg}^{2+}, \mathrm{CO}_{3}{ }^{2-}, \mathrm{K}^{+}, \mathrm{Na}^{+}$, $\mathrm{SiO}_{4}{ }^{4-}$ ), each of them carrying out specific functions active in the formation of new bone [12-31]. The nucleation of mineral nanocrystals initiates in specific loci corresponding to the gap between the collagen molecules that act as an organic template transferring information to the mineral phase $[13,15,16,32,33]$. Recently biologically inspired biomineralization processes were carried out in laboratory, thus achieving hybrid HA/collagen osteochondral scaffolds that when implanted in osteochondral defects resulted able to recruit progenitor cells from the bloodstream and direct their differentiation to the proper phenotype (i.e., bone or cartilage) thus yielding reconstruction of different anatomical regions [34-36]. The present work aims to explore the physicochemical and ultrastructural features inherent to such in-lab performed biomineralization which, as the natural biological processes, drive the formation of bone-like hybrid constructs with enhanced bioactivity. Particularly, it will be evaluated how the control of $\mathrm{pH}$ during synthesis and the introduction of multiple ions relevant for the activation of the biologic processes can regulate the kinetics of collagen assembling and organization as well as the HA nucleation and crystallization, thus affecting crystal growth and the exposure (i.e., bioavailability) of the mineral phase.

\section{Materials and Methods}

The organic matrix mediating the mineralization process was developed starting from type I collagen (Coll) extracted from equine tendon, telopeptides-free and supplied as an aqueous acetic buffer solution stabilized at $\mathrm{pH}=3.5$ and containing $1 \mathrm{wt} \%$ of pure collagen. The Coll suspension was dispersed in a diluted phosphoric acid solution and dropped into a calcium hydroxide aqueous suspension also containing additional doping ions. Various compositions were defined in order to achieve crystallization of apatite nanocrystals with different stoichiometry, in turn resulting in hybrid composites with stoichiometric apatite (HA) and apatite with biomimetic content of doping ions (bHA).

Synthesis of hybrid composites with stoichiometric apatite (HA/Coll): $244 \mathrm{~mL}$ of $\mathrm{H}_{3} \mathrm{PO}_{4}(0.040 \mathrm{M})$ solution, added with $70 \mathrm{~g}$ of $1 \mathrm{wt} \%$ collagen gel, was dropped in a basic suspension containing $1.203 \mathrm{~g}$ of $\mathrm{Ca}(\mathrm{OH})_{2}$ in $184 \mathrm{~mL}$ of distilled water to yield a composite HA/Coll material in the ratio $70 / 30 \mathrm{wt} \%$.

Synthesis of composite with biomimetic apatite (bHA/Coll): the same mineralization process was performed to nucleate $\mathrm{Mg}^{2+}, \mathrm{SiO}_{4}{ }^{4-}$-doped $\mathrm{HA}$ on the collagen fibers. In particular, $244 \mathrm{~mL}$ of $\mathrm{H}_{3} \mathrm{PO}_{4}(0.040 \mathrm{M})$ solution, mixed with $70 \mathrm{~g}$ of $1 \mathrm{wt} \%$ collagen gel, was dropped in a basic suspension containing $1.27 \mathrm{~g}$ of $\mathrm{Ca}(\mathrm{OH})_{2}$ (95\% pure), $0.58 \mathrm{~g}$ of $\mathrm{MgCl}_{2} \cdot 6 \mathrm{H}_{2} \mathrm{O}(99.5 \%$ pure) $[\mathrm{Mg} / \mathrm{Ca}$ molar ratio $=0.15$ ], and $0.138 \mathrm{~g}$ of $\mathrm{Si}\left(\mathrm{CH}_{3} \mathrm{COO}\right)_{4}$ (TEOS: $98 \%$ pure) in $200 \mathrm{~mL}$ of distilled water $[\mathrm{Si} / \mathrm{P}$ molar ratio $=0.05]$. All reactants are provided by Sigma-Aldrich (S. Louis, MO, USA). The amounts of $\mathrm{MgCl}_{2} \cdot 6 \mathrm{H}_{2} \mathrm{O}$ and TEOS were calculated in order to obtain the molar ratio $(\mathrm{Mg} / \mathrm{Ca})=5 \%$ and $\left(\mathrm{Si} / \mathrm{PO}_{4}\right)=$ $0.4 \%$ in the mineral phase.

The dropwise addition procedure was performed under stirring and assuring a slow decrease of $\mathrm{pH}$ up to neutrality (total dropping time for the considered volumes $\sim 30 \mathrm{~min}$ ). The final scaffolds were obtained by controlled freeze drying where freezing and heating ramps were performed from $25^{\circ} \mathrm{C}$ to $-25^{\circ} \mathrm{C}$ and from $-25^{\circ} \mathrm{C}$ to $25^{\circ} \mathrm{C}$ in 36 hours under vacuum conditions ( $P=0.20 \mathrm{mbar})$.

2.1. Chemicophysical Morphological Characterization. X-ray diffraction patterns (XRDs) were recorded by a Bruker AXS D8 Advance instrument in reflection mode $(\mathrm{Cu}-\mathrm{K} \alpha$ radiation). The samples were ground through a cryomilling apparatus to obtain relatively uniform particle size powder. Infrared spectroscopy (FTIR) was performed by using a Nicolet 4700 Spectroscopy on pellets $(13 \mathrm{~mm} \varnothing)$ which were prepared by mixing $2 \mathrm{mg}$ of ground sample with $100 \mathrm{mg}$ of $\mathrm{KBr}$ in a mortar and pressing. The composites were also examined by scanning electron microscopy (SEM; Stereoscan 360, Leica, Cambridge, UK). ICP-OES quantitative analysis, by using an inductively coupled plasma-atomic emission spectrometry (ICP-AES: Liberty 200, Varian, Clayton South, Australia), was applied to determine the content of $\mathrm{Ca}^{2+}$, $\mathrm{PO}_{4}{ }^{3-}, \mathrm{Mg}^{2+}$, and $\mathrm{Si}^{4+}$ ions in the mineral phase. The samples were previously dissolved in nitric acid $(65 \mathrm{wt} \%)$. Thermogravimetric analysis (Netzsch Gerätebau, STA449, Selb, Germany) was carried out to explore the thermal behavior of the composites and to assess the amount of mineral phase. This analysis was performed on specimens of about $20 \mathrm{mg}$ and using a heating rate of $10^{\circ} \mathrm{C} \mathrm{min}^{-1}$ up to $1000^{\circ} \mathrm{C}$ in air flow. Observations of composite materials by transmission electron microscopy (TEM) were performed with a JEOL EX4000 instrument with acceleration potential of $400 \mathrm{kV}$. Samples were dispersed on lacy carbon $\mathrm{Cu}$ grids by contact with the grids and subsequent gentle shaking. Timeresolved microscopic analysis of the biomineralization process was carried out by Cryo-TEM (CM12, FEI, Eindhoven, The Netherlands). For this analysis the synthesis of hybrid composites was performed on the TEM grid, covered with holey carbon thin film; $5 \mu \mathrm{L}$ of $\mathrm{Ca}(\mathrm{OH})_{2}$ suspension and $5 \mu \mathrm{L}$ of acid collagen solution were deposited on the grid, at defined $\mathrm{Ca} / \mathrm{P}$ molar ratios. After a blotting step to remove the 
excess of liquid, the synthesis was stopped at predetermined moments by freezing the intermediate product by an ethane bath, and then the resulting specimen was transferred to a cryo-holder and observed.

2.2. Cell Culture and Scaffold Seeding. MG-63 Human Osteoblast-like cells purchased by Lonza (Italy) were cultured in Dulbecco Modified Eagle's Medium (DMEM, PAA, Austria), containing penicillin/streptomycin $(100 \mathrm{U} / 100 \mu \mathrm{g} / \mathrm{mL})$, supplemented with $10 \%$ fetal bovine serum, and kept at $37^{\circ} \mathrm{C}$ in an atmosphere of $5 \% \mathrm{CO}_{2}$. Cells were detached from culture flasks by trypsinization and centrifuged; cell number and viability were assessed with trypan-blue dye exclusion test.

Scaffolds were $5.00 \mathrm{~mm}$ diameter and $6.00 \mathrm{~mm}$ high, sterilized by $25 \mathrm{kGy} \gamma$-ray radiation prior to use. Scaffolds were placed one per well in a 24-multiwell plate well and presoaked in culture medium. Each scaffold was seeded by carefully dropping $20 \mu \mathrm{L}$ of cell suspension $\left(5 \times 10^{4}\right.$ cells) onto the scaffold upper surface, and allowing cell attachment for $20 \mathrm{~min}$, before addition into each well of $1 \mathrm{~mL}$ of cell culture medium supplemented with $10 \mu \mathrm{g} / \mathrm{mL}$ ascorbic acid and $5 \mathrm{mM} \beta$-glycerophosphate for osteoblast activation. After a $6 \mathrm{~h}$ incubation step, each scaffold was carefully placed in a new 24 multiwell plate to eliminate any contribution of remnant cells from the cell suspension that might grow into the scaffold from its bottom surface. The medium was changed every 2 days. All cell-handling procedures were performed in a sterile laminar flow hood. All cell culture incubation steps were performed at $37^{\circ} \mathrm{C}$ with $5 \% \mathrm{CO}_{2}$. The medium was changed every 2 days for the duration of the experiment. Samples $(n=9)$ were analyzed at day 7 and equally distributed between the following tests.

2.3. Cell Viability Assay. Live/dead Viability/Cytotoxicity assay kit for mammalian cells (Invitrogen) was performed according to manufacturer's instructions. Briefly, scaffolds were washed with $1 \mathrm{x}$ PBS for $5 \mathrm{~min}$ and incubated with Calcein acetoxymethyl (Calcein AM) $2 \mu \mathrm{M}$ plus Ethidium homodimer-1 (EthD-1) $4 \mu \mathrm{M}$ for $15 \mathrm{~min}$ at $37^{\circ} \mathrm{C}$ in the dark. Samples were rinsed in $1 x$ PBS, finely cut with a scalpel in order to examine also the internal surface and images acquired by an inverted Nikon Ti-E fluorescence microscope (Nikon).

2.4. Cell Morphology Analysis. Actin immunofluorescence: samples were washed with 1x PBS for 5 min, fixed with $4 \%$ $(\mathrm{w} / \mathrm{v})$ paraformaldehyde for $15 \mathrm{~min}$, and washed with $1 \mathrm{x}$ PBS for $5 \mathrm{~min}$. Permeabilization was performed with 1x PBS with $0.1 \%(\mathrm{v} / \mathrm{v})$ Triton X-100 for $15 \mathrm{~min}$. FITC-conjugated Phalloidin antibody (Invitrogen) 1:500 in 1x PBS was added for $30 \mathrm{~min}$ at $37^{\circ} \mathrm{C}$ in the dark. Samples were washed with 1x PBS for $5 \mathrm{~min}$ and incubated with $300 \mathrm{nM}$ DAPI solution (Invitrogen) for $5 \mathrm{~min}$. Samples were washed with $1 \mathrm{x}$ PBS for $5 \mathrm{~min}$ and then finely cut with a scalpel in order to examine also the internal morphology. Analysis and imaging were performed by an Inverted Nikon Ti-E fluorescence microscope (Nikon).
SEM characterization: cell-seeded scaffolds were imaged and characterized using a SEM Stereoscan 360 Scanning Electron Microscope (Cambridge Instruments, UK). Samples were washed with $0.1 \mathrm{M}$ sodium cacodylate buffer $\mathrm{pH} 7.4$ and fixed in $2.5 \%$ glutaraldehyde in $0.1 \mathrm{M}$ sodium cacodylate buffer $\mathrm{pH} 7.4$ for $2 \mathrm{~h}$ at $4^{\circ} \mathrm{C}$, washed in $0.1 \mathrm{M}$ sodium cacodylate buffer $\mathrm{pH}$ 7.4, and freeze dried. Samples were finely cut with a scalpel in order to examine also the internal morphology and then sputter coated with gold using a Polaron Range sputter coater (DentonVaccum, USA) and mounted on a copper grid to be examined at SEM.

\section{Results}

3.1. Physicochemical, Morphological, and Ultrastructural Features. The XRD spectra of the mineralized construct (Figure 1) put in evidence the formation of a low crystalline mineral phase with the structure of hydroxyapatite (HA) (ICDD card no. 09-0432), superimposed to a broad spectrum belonging to the collagen matrix. The broadening of the XRD pattern belonging to HA is due to the very small crystal size, estimated as $10-15 \mathrm{~nm}$. No secondary phases were detected besides hydroxyapatite, even in case of biomineralization with biomimetic HA where a nearly amorphous phase was detected (Figure 1(b)), thus confirming that ions were incorporated in the apatite structure.

FTIR analysis highlights that the mineral phase is heterogeneously nucleated on the collagen matrix, in correspondence to the carboxyl group. In fact in FTIR spectrum of the hybrid composite (Figure 2) a shift from 1340 to $1337 \mathrm{~cm}^{-1}$ in the absorption band corresponding to $-\mathrm{COO}^{-}$stretching is evident, due to the chemical interaction with $\mathrm{Ca}^{2+}$ surface site of the apatite lattice [32].

FTIR spectra also put in evidence the low crystal order of the mineral phase, particularly in case of heterogeneous nucleation of bHA, also confirming the results obtained by XRD analysis. Indeed, the absorption bands related to phosphate, which are located at about 630,600 , and $550 \mathrm{~cm}^{-1}$ [37] are poorly defined and merge into a single broad band. Moreover, the broad band at about 550$600 \mathrm{~cm}^{-1}$, assigned to $\mathrm{HPO}_{4}{ }^{2-}$, becomes more intense in case of biomimetic mineral phase. These features are typical of young and immature bone where the low crystallinity of the mineral phase results in high biological activity [37-39]. FTIR spectrum also evidences carbonation of the apatite phase, specifically in B position (i.e., phosphate site), due to the presence of the related absorption band at $870 \mathrm{~cm}^{-1}$ [37]; moreover no evidence of absorption at $880 \mathrm{~cm}^{-1}$ is evident, thus highlighting that carbonation in A position (i.e., hydroxyl site) resulted in being prevented, probably due to steric hindrance by the collagenous matrix that hampered access to the $\mathrm{OH}^{-}$sites of the mineral phase. Chemical analysis (Table 1) further confirms the occurred carbonation, since an increase of carbon was always accompanied by a reduction in phosphorus.

The estimated carbonation is consistent with the weight loss detected in our hybrid composites upon heating at $1000^{\circ} \mathrm{C}$ (see Figure 3). The analysis of weight loss also 


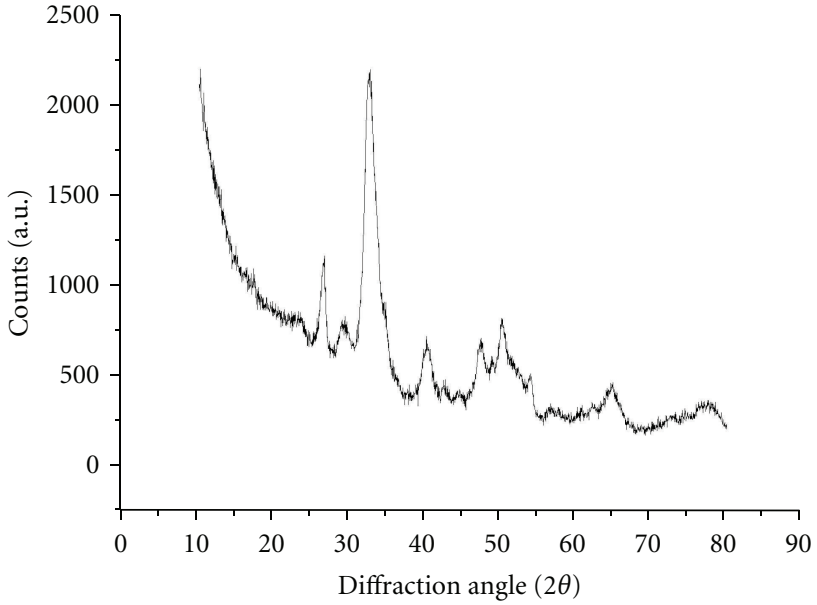

(a)

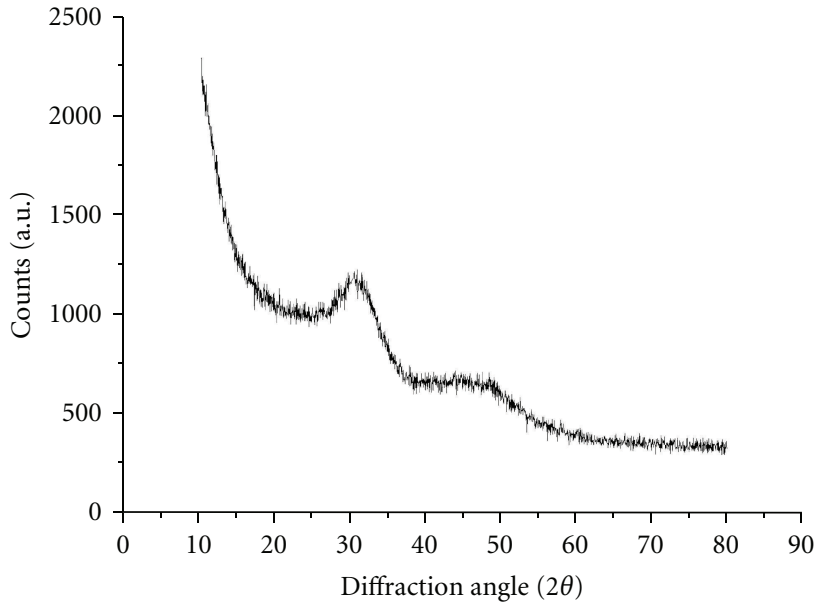

(b)

FIgURE 1: XRD spectra of hybrid biomineralized constructs. (a) Stoichiometric HA phase; (b) biomimetic HA phase.

TABLE 1: Composition of the mineral phase in HA/Coll and bHA/Coll scaffolds in comparison with human bone.

\begin{tabular}{lcccc}
\hline & Typical composition of human bone (wt\%) & Introduced ions (wt\%) & Actual HA/Coll (wt\%) & Actual bHA/Coll (wt\%) \\
\hline $\mathrm{Ca}^{2+}$ & 24.36 & 27.98 & 26.06 & 25.54 \\
$\mathrm{PO}_{4}{ }^{3-}$ & 32.62 & 39.79 & 36.04 & 31.78 \\
$\mathrm{Si}^{4+}$ & $0.29-0.58$ & 0.63 & - & 0.41 \\
$\mathrm{Mg}^{2+}$ & $0.35-0.91$ & 2.96 & - & 0.53 \\
$\mathrm{CO}_{3}{ }^{2-}$ & $2.1-5.6$ & - & $>2$ & $>2$ \\
\hline
\end{tabular}

shows that in nucleated bHA higher amounts of water are coordinated to the mineral phase by physical or chemical bonds, compared to stoichiometric mineral phase, thus evidencing a higher density of active sites as well as increased affinity with water molecules.

The multiple ionic substitutions in the apatite heterogeneously nucleated on the collagen matrix are assessed by chemical analysis, which put in evidence that when biomineralization is carried out in presence of magnesium and silicate ions, the resulting mineral phase exhibits a bonelike composition (Table 1), even in case of introduction of higher amount of $\mathrm{Mg}^{2+}$ and $\mathrm{SiO}_{4}{ }^{4-}$ ions in the reaction flask. This feature is also confirmed by thermogravimetric analysis carried out on hybrid composites mineralized with both stoichiometric and biomimetic HA to determine the maximum amount of mineral phase which could be heterogeneously nucleated on the collagen matrix. The samples selected for this analysis were obtained by biomineralization with high amounts of $\mathrm{Ca}^{2+}$ and $\mathrm{PO}_{4}{ }^{3-}$ so as to overcome the upper limit for the mineral phase that can be heterogeneously nucleated and to obtain precipitation of excess mineral phase. On the basis of the detected weight loss (Figure 3 ) it is determined that the maximum amount of mineral phase that can be heterogeneously nucleated by biologically inspired mineralization is about $70 \mathrm{wt} \%$, that is, a typical bonelike composition. Microscopic observations carried out by TEM further confirm the formation of the mineral phase by heterogeneous nucleation; TEM micrographs show nanosized nuclei formed inside the collagen fibres and growing parallel to fibres (Figure 4). This feature is accompanied by a preferential orientation of HA crystals, detected by flat film XRD analysis carried out on calcified fibres (Figure 5); in particular the (002) reflection of $\mathrm{HA}$, detected at $0.34 \mathrm{~nm}$, preferentially orients parallel to the direction of orientation of the typical collagen molecular axial spacing at $0.29 \mathrm{~nm}$. When analysing hybrid composites biomineralized with stoichiometric HA, it can be observed that the growth of HA nuclei proceeds towards development of acicular nanosized grains (Figure 4(a)). Conversely, when the mineral phase has a bone-like composition, HA nuclei exhibit a globular-like shape and very short-range crystal order (Figure 4(b)), as evidenced by Fourier-transform analysis of HRTEM images, thus exhibiting features of a nearly amorphous calcium phosphate (see also XRD analysis in Figure 1).

Deeper investigation on the biomineralization process, carried out by time-resolved cryo-TEM observations in function of $\mathrm{pH}$ variation, evidences that at low $\mathrm{pH}$ the organization of fibres is still at a preliminary stage (Figure 6(a)); then, by increasing $\mathrm{pH}$ during the biomineralization process the fibres assume the typical banding pattern of organized collagen showing local disorder in correspondence of the mineral nuclei (Figure 6(b)), which result located at the gaps between collagen molecules.

Further evidence of inner mineralization of assembled collagen fibres comes from SEM observation of hybrid composites thermally treated at $1000^{\circ} \mathrm{C}$ during thermogravimetric analysis. In particular Figure 7 shows that HA particles occupied the whole volume of the construct; more 


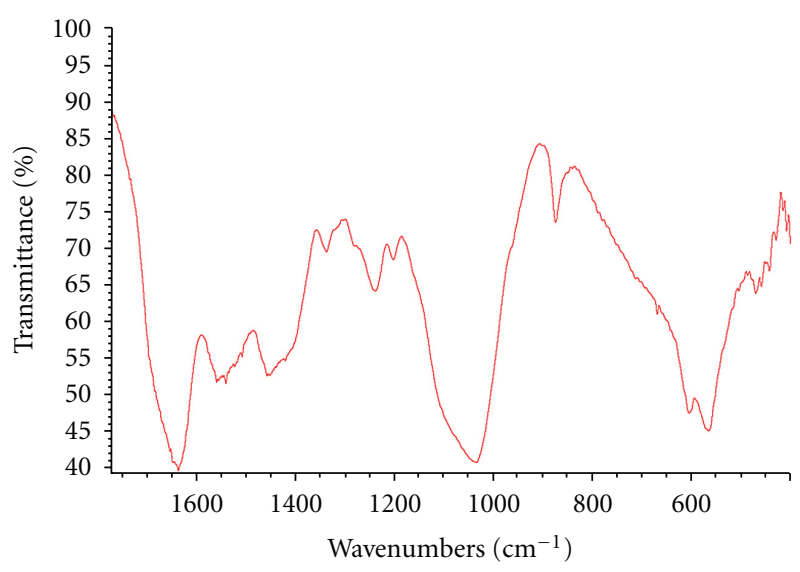

(a)

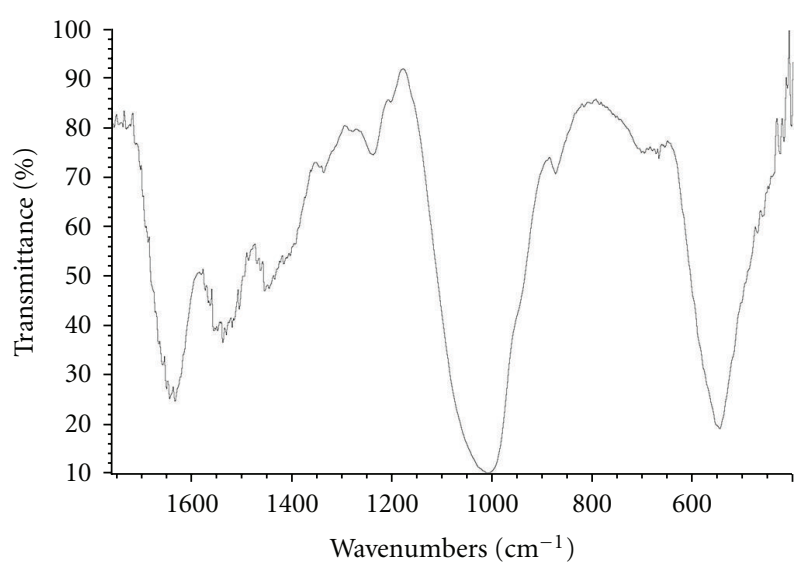

(b)

FIGURE 2: FTIR spectra of hybrid composite mineralized with (a) stoichiometric HA; (b) bHA.

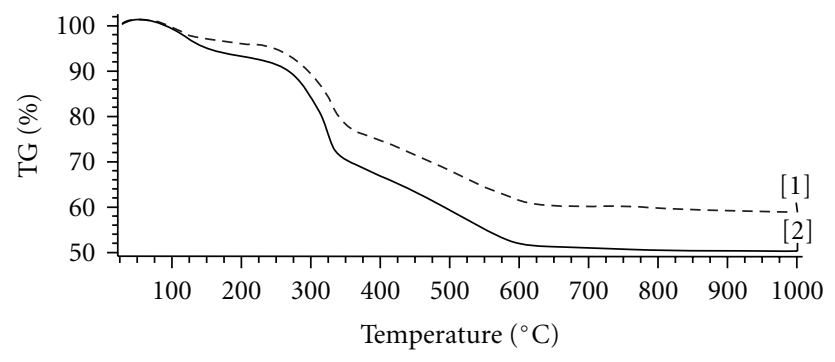

FIGURE 3: TG analysis of hybrid composites reporting weight loss of stoichiometric HA (dashed line) and bHA (continuous line).

in detail, it is noticeable that the HA particles assume a prismatic shape in case of stoichiometric composition (Figure 7(a)), whereas they become nearly globular in case of mineralization with multisubstituted HA (Figure 7(b)).

3.2. Analysis of Cell Behaviour. MG-63 human osteoblastlike cells were cultured within the hybrid HA/Coll composites for 7 days. The live/dead assay showed a very high ratio of viable cells on scaffold surface. Cells cover nearly the entire upper scaffold surface, and they grew into the porous scaffold structure and infiltrated the scaffolds as shown in Figure 8(a). The analysis of cell morphology showed a very tight relationship between osteoblast cells and the mineralized collagen fibres (Figures 8(b) and 9). Attached cells exhibited their characteristic intricate morphology analysed by phalloidin staining on day 7 (Figure 8(b)). Moreover SEM images showed human osteoblast-like cells completely embedded within the nanostructure of the hybrid collagen-HA construct (Figure 9). It was observed the cells capability of adhering and spreading over single-collagen fibers, which impose directionality, as if cells were dangling on collagen (Figures 9(a) and 9(b)). Cells and biomaterials seemed to coalesce thus illustrating the high biocompatibility and osteoconductivity performances of the hybrid construct (Figure 9(c)).

\section{Discussion}

The synthesis process adopted for in-lab biomineralization is based on dropwise addition of acidic collagen suspensions containing phosphate ions into a basic suspension under continuous stirring. This resulted in a locally occurring neutralization process whereas the overall $\mathrm{pH}$ in the reaction flask was maintained nearly constant at $\mathrm{pH} \sim 12$ due to the $\mathrm{Ca}(\mathrm{OH})_{2}$ suspension. The average $\mathrm{pH}$ in the small volume where neutralization took place resulted steeply in increasing from $\sim 2.5$ to 10 .

Within this range, particularly from 4.5 to 6.5 the dispersed nanosized collagen fibrils start their assembling, thus giving rise to formation of progressively thicker and more organized fibres; on the other hand, at higher $\mathrm{pH}$ values (i.e., $\mathrm{pH} \geq 5.5$ ) the formation of hydroxyapatite crystals, supported by $\mathrm{Ca}^{2+}$ and $\mathrm{PO}_{4}{ }^{3-}$ ions dispersed in the solution, was thermodynamically favoured against other calcium phosphates. When collagen comes in contact with $\mathrm{Ca}^{2+}$ ions, they soon link to $\mathrm{COO}^{-}$groups exposed by C-terminal regions of tropocollagen fibrils, so that the formation of apatite crystals is initiated by phenomena of heterogeneous nucleation. This process involves the same functional groups responsible for the assembling of collagen fibrils; thus, the free sites for heterogeneous nucleation of the mineral phase result in being those located in the periodically spaced gaps which form along the staggered collagen fibrils during their assembling and organization [5, 32, 40, 41].

The fast local increase of $\mathrm{pH}$ from acidic to slightly basic values allows to achieve the formation of HA nuclei onto the newly formed collagen matrix; in particular, since the two $\mathrm{pH}$ ranges where fibres assembling and HA nucleation, respectively, occur are not completely distinct, amorphous HA nuclei form onto the fibrils before their complete assembling into more organized fibres. Upon further increase of $\mathrm{pH}$ two processes enter in competition, that is, (i) the organization of collagen fibers into a three-dimensional network and (ii) the proceeding HA crystallization, involving the same binding chemical groups on the fibres surface. Cryo-TEM observations well describe this scenario, where the organization of 


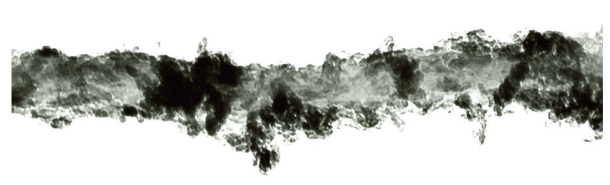

$200 \mathrm{~nm}$

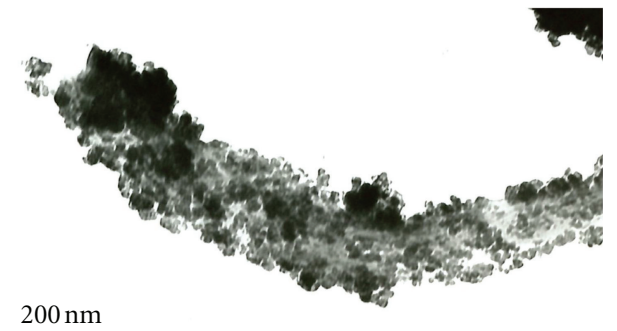

(a)

(b)

FIGURE 4: TEM micrographs of collagen fibres. (a) Mineralized with stoichiometric HA; (b) mineralized with biomimetic HA.

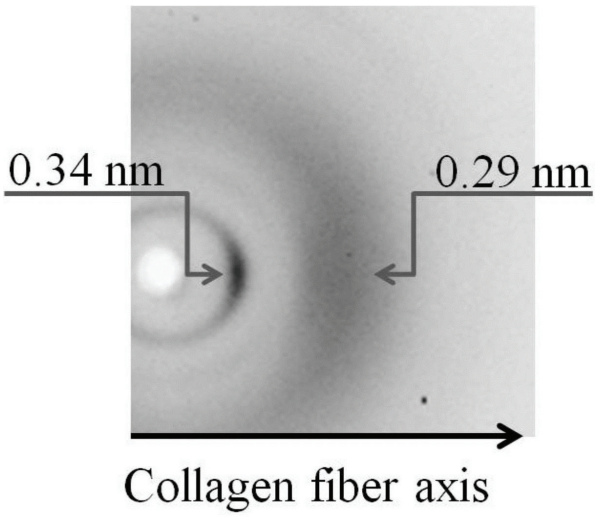

FIGURE 5: Flat film XRD pattern of a thin bundle of parallel calcified fibers, evidencing the orientation of HA (002) reflection along the axial collagen fibers direction.

collagen fibres appears in progress whereas at $\mathrm{pH}$ above 5.5 the formation of mineral nuclei initiates and provokes a local distortion in correspondence to the band gaps. Even if such a biomineralization process is carried out in stoichiometric conditions (i.e., amount of reactants calculated to obtain HA phase with $\mathrm{Ca}_{10}\left(\mathrm{PO}_{4}\right)_{6}(\mathrm{OH})_{2}$ composition), the crystallization of the mineral phase is prevented owing to the contact with the collagen surface. Indeed, the interaction with the collagenous matrix at the nanoscale is mediated by ultrastructural, chemotactic, and physical constraints affecting crystal growth and organization of the mineral phase. In particular, the crystal structure of the mineral phase results in being characterized by amorphous or very short-range order; in addition, the topotactic information provided by the collagenous matrix at the sites of heterogeneous nucleation induces preferential crystal growth of the HA-hexagonal crystals with $c$ axis elongated along the long axis of collagen. As a consequence the crystallographic $a b$ plane of the newly formed HA phase results in being exposed perpendicularly to the long axis of the collagen fibers; this feature is supposed to promote specific adsorption of proteins specifically involved in new bone formation [5]. Besides the structural control, a chemical control mechanism is also active in our biomineralization process; in fact $\mathrm{CO}_{3}{ }^{2-}$ ions partially replace $\mathrm{PO}_{4}{ }^{3-}$ ions (B-site carbonation) in the lattice of the nucleated apatite phase; the chemical substitution in B position is commonly detected in young and immature bone and is known to promote the establishment of chemotactic and polarity features at the surface level which favor osteoblast adhesion. The carbonation in B position results in being selectively imposed by the physical constraints inherent to the polymeric matrix, thus preventing the incorporation of $\mathrm{CO}_{3}{ }^{2-}$ ions in $\mathrm{OH}^{-}$sites (A-site carbonation), which is known to confer stability to the mineral phase and is commonly found predominantly in mature bone.

In presence of additional foreign ions $\left(\mathrm{Mg}^{2+}\right.$ and $\left.\mathrm{SiO}_{4}{ }^{4-}\right)$ introduced in the reaction flask during in-lab biomineralization, the crystal disorder of the heterogeneously nucleated HA particles favours their incorporation and substitution of $\mathrm{Ca}^{2+}$ and $\mathrm{PO}_{4}{ }^{3-}$, respectively, in the apatite structure thus forming a biomimetic HA strongly mimicking in composition the inorganic part of human bone. Such ions are present in the mineral phase of young and immature bone and have relevant function in the formation of new bone. In this respect $\mathrm{Mg}^{2+}$ ions have a specific role in guiding the processes of new bone formation; in particular, it is well known that ionic substitution with $\mathrm{Mg}^{2+}$ ions promotes nucleation phenomena while preventing grain growth, so that the mineral phase results in being organized in a very high number of nanonuclei so as to provide increased bioavailability [18]. Indeed surface $\mathrm{Mg}^{2+}$ sites exhibit different polarity, structure and stereochemistry that also result in stronger coordination with $\mathrm{H}_{2} \mathrm{O}$ molecules, compared to $\mathrm{Ca}^{2+}$ [23], which in turn affects the ability of favouring protein adhesion. Moreover, in our observation the introduction of $\mathrm{Mg}^{2+}$ ions favoured the chemical link of the mineral phase with collagen in correspondence to the band gaps, which is likely due to the increase of nucleation kinetics. In this respect previous works have shown that the presence of polyelectrolytes during inlab biomineralization can mimic the function of noncollagenic acidic macromolecules in the guidance of mineral phase nucleation in the band gap [42]; in consequence we can suppose that $\mathrm{Mg}^{2+}$ ions present in newly formed human bone can have a further relevant role in biological processes and can act in the same way as polyelectrolytes during in-lab biomineralization.

Besides, the incorporation of silicon in the phosphate site further increased biomimesis and affinity with the newly formed bone since silicon is associated with the formation 


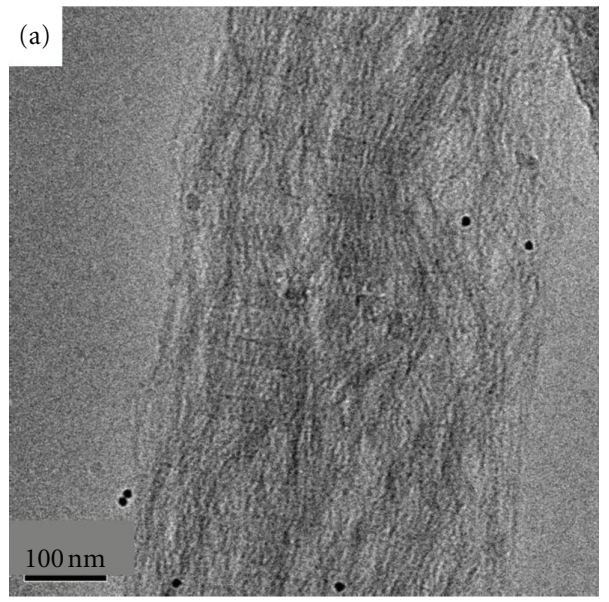

(a)

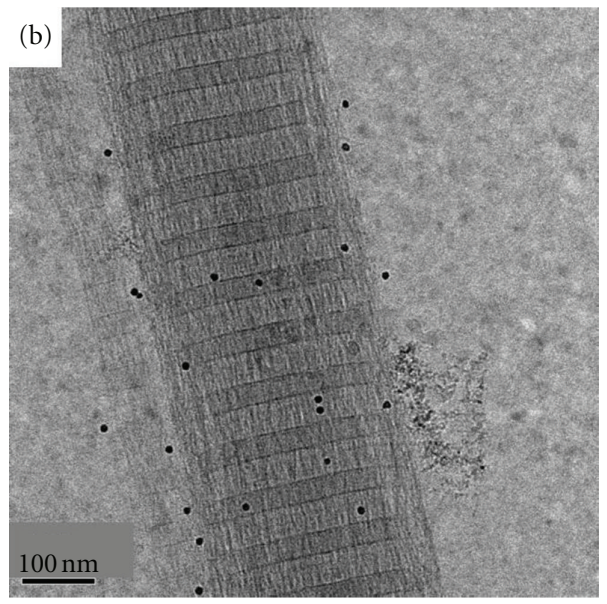

(b)

Figure 6: Cryo-TEM images of a collagen fiber during biomineralization. (a) At a first stage of the reaction; (b) at an advanced stage.

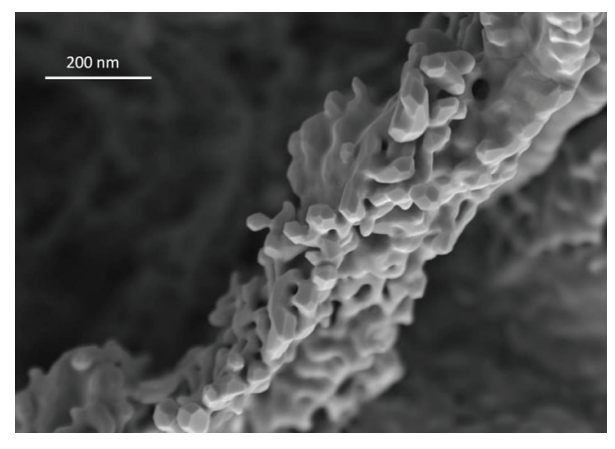

(a)

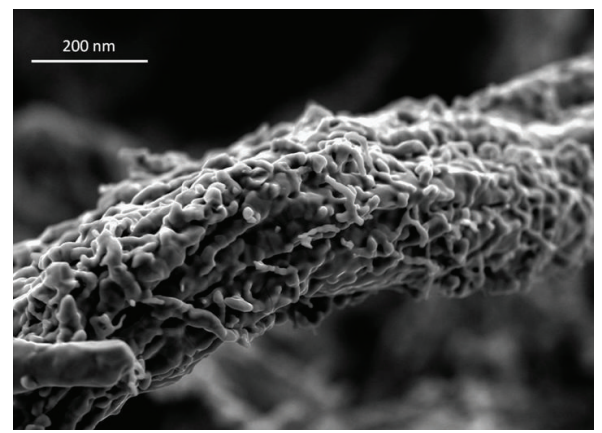

(b)

FIGURE 7: SEM micrographs of mineralized collagen fibers after heating at $1000^{\circ} \mathrm{C}$.

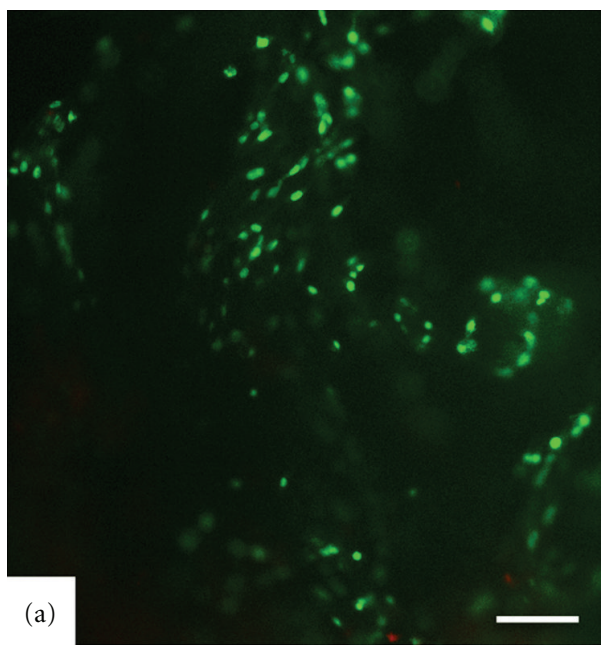

(a)

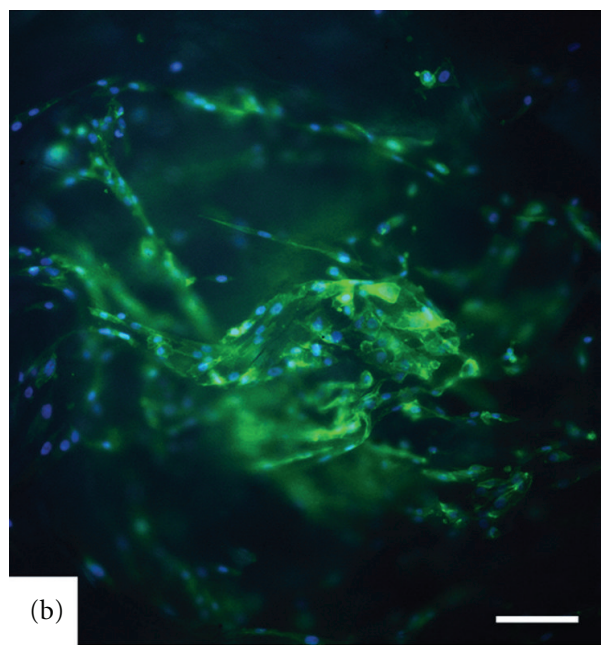

(b)

FIGURE 8: Analysis of cell viability and morphology. (a) Cell viability was analysed by the live/dead assay (calcein acetoxymethyl stains live cells in green ethidium homodimer-1 stains dead cells in red). (b) Cell morphology was analysed by actin staining (actin is shown in green, DAPI in blue). Scale bars: $100 \mu \mathrm{m}$. 


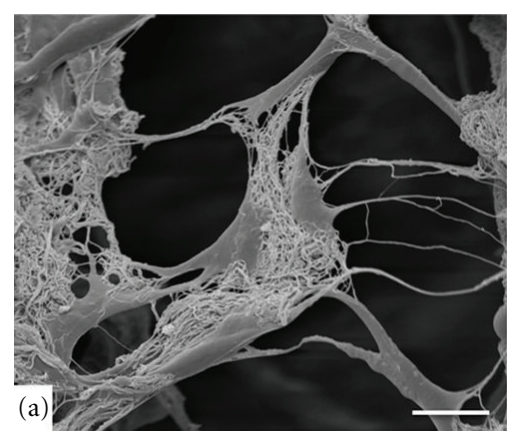

(a)

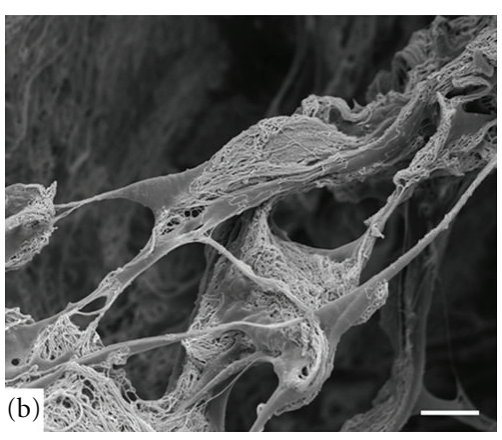

(b)

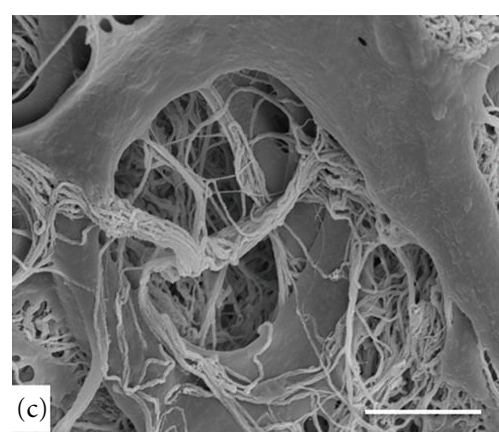

(c)

FIGURE 9: SEM analysis. Detailed analysis of morphology of biohybrid scaffold. (a and b) Intricate mesh of cells and HA/collagen fibers. (c) Higher magnification picture showing completely embedded cells within the nanostructure of a bioinspired collagen-HA scaffold. Scale bars: (a and b) $20 \mu \mathrm{m}$; (c) $10 \mu \mathrm{m}$.

of cross-links between collagen and proteoglycans [21] in the early stages of bone formation, in turn leading to bone matrix stabilization against enzymatic resorption.

With these multiple substitutions, the composition of mineral phase in our in-lab biomineralized composites results in being very close to the one of natural bone, that is,

$$
(\mathrm{Ca}, \mathrm{Mg})_{10-x / 2}\left(\mathrm{PO}_{4}\right)_{6-x-y}\left(\mathrm{CO}_{3}\right)_{x}\left(\mathrm{SiO}_{4}\right)_{y}(\mathrm{OH})_{2-2 y} .
$$

The expression of ultrastructural mimesis with bone in our hybrid composites was found to depend on the presence of biomimetic ions. In fact, the introduction of substituting ions during the process of heterogeneous nucleation not only affected composition but also crystal growth. In particular the interaction with collagen and the presence of magnesium activate topotactic control mechanisms which drive specific preferential orientation and growth of the mineral phase.

All the above-described features, expressing chemicophysical, morphological, and ultrastructural mimesis with the newly formed human bone, were achieved due to the different control mechanisms inherent to the polymeric matrix that were activated during the in-lab performed biomineralization.

Such process confers to the mineral phase features that cannot be achieved by conventional methods of powder synthesis. In fact, even though low-crystalline HA nanoparticles with biomimetic composition can be obtained by wet methods at room temperature, in such particles a crystal-like order is always detected [30]; moreover the peculiar shape and size of the mineral phase driving specific cell behaviour can be only achieved by mediation of the information provided at the nanosize by the collagenous template. In this respect, when in biomimetic conditions, the collagenous matrix self-assemble and organize, thus providing an ensemble of control mechanisms that unambiguously determine the characteristics of the mineral phase, in turn driving new bone formation.

A further evidence that our in-lab biomineralization is consistent with biological processes of bone formation is in the intrinsic stability of the 3-D hybrid construct versus mineral/polymer ratio. Indeed, our hybrid system, intended as bHA nanoparticles heterogeneously nucleated on a selfassembled collagen matrix, resulted in being stable only when mineral/polymer ratio was consistent with the composition of natural mineralized tissues. In fact, the amount of the mineral phase in the composite can be controlled by adjusting the composition of the starting solutions in terms of $\mathrm{Ca}^{2+}$ and $\mathrm{PO}_{4}{ }^{3-}$ ions, in turn determining the final amount of apatite phase; in this respect, it was observed that precipitation of the mineral phase during synthesis in biomimetic conditions occurred when in concentrations above $\approx 70 \mathrm{wt} \%$, that is, a bone-like composition. This means that, in our 3-D biomineralized constructs, the amount of mineral phase that can nucleate and grow, driven by information provided by the collagen matrix, is intrinsically defined and limited to bone-like composition.

Cell-surface interaction includes specific chemicophysical linkages between cells and material, where cell adhesion and spreading pave the way to cell proliferation, finally providing a surface well covered by cells. Cell-material surface interaction and cell adhesion are complex processes involving the reorganization of cytoskeleton proteins further stimulated in this case by the ordered alignment of needlelike HA crystals along their $c$ axis on collagen fibers. The SEM images in Figures 9(a) and 9(b) are emblematic of how much the cells like such a biomimetic substrate so that they actually "go on swing" with its biomineralized collagen fibers.

The possibility to vary the mineralization degree over a wide range up to bone-like composition offers a significant tool to develop graded constructs able to mimic different anatomical regions in hard connective tissues such as bones or teeth. In particular, the different compartment of articular regions, namely, subchondral bone, mineralized cartilage, and hyaline cartilage, can be accurately mimicked to achieve biomimetic scaffolds for osteochondral regeneration [34]. Moreover, the possibility to vary the degree of fibration and assembling of collagen fibers makes possible to develop chemically and morphologically graded scaffolds mimicking the different components of dentin (i.e., pulp, predentin, mineralized dentin) and of periodontal bone (i.e., cementum, alveolar bone, and periodontal ligament).

In contact with such graded scaffolds, mesenchymal stem cells receive information which guides their selective 
differentiation into osteoblasts or chondrocytes. In particular, when implanted in vivo the high porosity of the hybrid constructs allows cell recruitment from the bloodstream and subsequent colonization and proliferation, whereas the chemical and ultrastructural features of the mineral phase, strongly mimicking bone tissue, act as osteogenic signals [35]. In this respect, the absence of mineral phase in the cartilage-like layer promotes cell differentiation into chondrocytes, thus leading to in vivo regeneration of the cartilaginous part.

\section{Conclusions}

The achievement of scaffolds exhibiting strong mimicry with natural tissues is a key feature for hard tissue regeneration. However, conventional manufacturing processes suffer from strong limitations to achieve materials with high complexity and organization at the nanoscale. In this respect we have shown that, by soft chemistry procedures, it is possible to activate all the control mechanisms inherent to natural self-assembling polymers such as collagen and to direct biological-like mineralization processes towards formation of hybrid constructs with very high chemicophysical, morphological, and ultrastructural mimesis with the natural bone tissue. The high regenerative potential of such devices is due to the synergistic combination of the organic matrix and the mineral phase, whose osteogenic properties are conferred by specific chemical and topotactic features as well as by the physical confinement imposed by the organic matrix itself. The hybrid constructs can be flexibly addressed to specific designed functions, so that they can be designed to regenerate different anatomical districts.

\section{Acknowledgments}

The research leading to these results has received funding from the European Union's Seventh Framework Programme ([FP7/2007-2013]) under Grant agreement no. 246373, OPHIS. The authors gratefully acknowledge as well Prof. N. A. J. M. Sommerdijk and Dr. F. Nudelman, Technical University of Eindhoven, for valuable discussion and CryoTEM images.

\section{References}

[1] J. Aizenberg, J. C. Weaver, M. S. Thanawala, V. C. Sundar, D. E. Morse, and P. Fratzl, "Materials science: skeleton of euplectella sp.: structural hierarchy from the nanoscale to the macroscale," Science, vol. 309, no. 5732, pp. 275-278, 2005.

[2] Z. Y. Tang, N. A. Kotov, S. Magonov, and B. Ozturk, "Nanostructured artificial nacre," Nature Materials, vol. 2, no. 6, pp. 413-418, 2003.

[3] S. Deville, E. Saiz, R. K. Nalla, and A. P. Tomsia, "Freezing as a path to build complex composites," Science, vol. 311, no. 5760, pp. 515-518, 2006.

[4] E. Munch, M. E. Launey, D. H. Alsem, E. Saiz, A. P. Tomsia, and R. O. Ritchie, "Tough, bio-inspired hybrid materials," Science, vol. 322, no. 5907, pp. 1516-1520, 2008.
[5] S. Mann, Biomineralization Principles and Concepts in Bioinorganic Materials Chemistry, Oxford University Press, Oxford, UK, 2001.

[6] A. Tampieri, S. Sprio, M. Sandri, and F. Valentini, "Mimicking natural bio-mineralization processes: a new tool for osteochondral scaffold development," Trends in Biotechnology, 2011.

[7] H. A. Lowenstam and S. Weiner, On Biomineralization, Oxford University Press, New York, NY, USA, 1989.

[8] A. Berman, J. Hanson, L. Leiserowitz, T. F. Koetzle, S. Weiner, and L. Addadi, "Biological control of crystal texture: a widespread strategy for adapting crystal properties to function," Science, vol. 259, no. 5096, pp. 776-779, 1993.

[9] R. A. Metzler, G. A. Tribello, M. Parrinello, and P. U. P. A. Gilbert, "Asprich peptides are occluded in calcite and permanently disorder biomineral crystals," Journal of the American Chemical Society, vol. 132, no. 33, pp. 11585-11591, 2010.

[10] J. J. De Yoreo and P. G. Vekilov, "Principles of crystal nucleation and growth," in Biomineralization, P. M. Dove, J. J. DeYoreo, and S. Weiner, Eds., vol. 54, pp. 57-93, Mineralogical Society of America, Washington, DC, USA, 2003.

[11] E. M. Pouget, P. H. H. Bomans, J. A. C. M. Goos, P. M. Frederik, G. De With, and N. A. J. M. Sommerdijk, "The initial stages of template-controlled $\mathrm{CaCO}_{3}$ formation revealed by Cryo-TEM," Science, vol. 323, no. 5920, pp. 1455-1458, 2009.

[12] M. J. Olszta, X. Cheng, S. S. Jee et al., "Bone structure and formation: a new perspective," Materials Science and Engineering R, vol. 58, no. 3-5, pp. 77-116, 2007.

[13] S. V. Dorozhkin and M. Epple, "Biological and medical significance of calcium phosphates," Angewandte Chemie, vol. 41, no. 17, pp. 3130-3146, 2002.

[14] R. Z. LeGeros, "Calcium phosphates in oral biology and medicine," Monographs in oral science, vol. 15, pp. 1-201, 1991.

[15] Q. Zhang, J. Chen, J. Feng, Y. Cao, C. Deng, and X. Zhang, "Dissolution and mineralization behaviors of HA coatings," Biomaterials, vol. 24, no. 26, pp. 4741-4748, 2003.

[16] C. T. Laurencin, Ed., Bone Graft Substitutes, ASTM International, West Conshohocken, Pa, USA, 2003.

[17] A. L. Boskey, "Mineralization, structure and function of bone," in Dynamics of Bone and Cartilage Metabolism, M. J. Seibel, S. P. Robins, and J. P. Bilezikian, Eds., p. 201, Academic Press, New York, NY, USA, 2006.

[18] A. Bigi, E. Foresti, R. Gregorini, A. Ripamonti, N. Roveri, and J. S. Shah, "The role of magnesium on the structure of biological apatites," Calcified Tissue International, vol. 50, no. 5, pp. 439-444, 1992.

[19] N. B. Matsko, N. Žnidaršič, I. Letofsky-Papst et al., "Silicon: the key element in early stages of biocalcification," Journal of Structural Biology, vol. 174, no. 1, pp. 180-186, 2011.

[20] A. M. Pietak, J. W. Reid, M. J. Stott, and M. Sayer, "Silicon substitution in the calcium phosphate bioceramics," Biomaterials, vol. 28, no. 28, pp. 4023-4032, 2007.

[21] K. Schwarz, "A bound form of silicon in glycosaminoglycans and polyuronides," Proceedings of the National Academy of Sciences of the United States of America, vol. 70, no. 5, pp. 16081612, 1973.

[22] Y. Sakhno, L. Bertinetti, M. Iafisco, A. Tampieri, N. Roveri, and G. Martra, "Surface hydration and cationic sites of nanohydroxyapatites with amorphous or crystalline surfaces: a comparative study," Journal of Physical Chemistry C, vol. 114, no. 39, pp. 16640-16648, 2010.

[23] L. Bertinetti, C. Drouet, C. Combes et al., "Surface characteristics of nanocrystalline apatites: effect of $\mathrm{Mg}$ surface 
enrichment on morphology, surface hydration species, and cationic environments," Langmuir, vol. 25, no. 10, pp. 56475654, 2009.

[24] L. Bertinetti, A. Tampieri, E. Landi et al., "Surface structure, hydration, and cationic sites of nanohydroxyapatite: UHRTEM, IR, and microgravimetric studies," Journal of Physical Chemistry C, vol. 111, no. 10, pp. 4027-4035, 2007.

[25] L. Bertinetti, A. Tampieri, E. Landi, G. Martra, and S. Coluccia, "Punctual investigation of surface sites of HA and magnesiumHA," Journal of the European Ceramic Society, vol. 26, no. 6, pp. 987-991, 2006.

[26] G. Celotti, A. Tampieri, S. Sprio et al., "Crystallinity in apatites: how can a truly disordered fraction be distinguished from nanosize crystalline domains?" Journal of Materials Science, vol. 17, no. 11, pp. 1079-1087, 2006.

[27] E. Landi, A. Tampieri, M. Mattioli-Belmonte et al., "Biomimetic $\mathrm{Mg}$ - and $\mathrm{Mg}, \mathrm{CO}_{3}$-substituted hydroxyapatites: synthesis characterization and in vitro behaviour," Journal of the European Ceramic Society, vol. 26, no. 13, pp. 2593-2601, 2006.

[28] E. Landi, A. Tampieri, G. Celotti, R. Langenati, M. Sandri, and S. Sprio, "Nucleation of biomimetic apatite in synthetic body fluids: dense and porous scaffold development," Biomaterials, vol. 26, no. 16, pp. 2835-2845, 2005.

[29] E. Landi, A. Tampieri, G. Celotti, L. Vichi, and M. Sandri, "Influence of synthesis and sintering parameters on the characteristics of carbonate apatite," Biomaterials, vol. 25, no. 10, pp. 1763-1770, 2004.

[30] S. Sprio, A. Tampieri, E. Landi et al., "Physico-chemical properties and solubility behaviour of multi-substituted hydroxyapatite powders containing silicon," Materials Science and Engineering C, vol. 28, no. 1, pp. 179-187, 2008.

[31] E. Landi, S. Sprio, M. Sandri, G. Celotti, and A. Tampieri, "Development of $\mathrm{Sr}$ and $\mathrm{CO}_{3}$ co-substituted hydroxyapatites for biomedical applications," Acta Biomaterialia, vol. 4, no. 3, pp. 656-663, 2008.

[32] A. Tampieri, G. Celotti, E. Landi, M. Sandri, N. Roveri, and G. Falini, "Biologically inspired synthesis of bone-like composite: self-assembled collagen fibers/hydroxyapatite nanocrystals," Journal of Biomedical Materials Research A, vol. 67, no. 2, pp. 618-625, 2003.

[33] A. Tampieri, G. Celotti, and E. Landi, "From biomimetic apatites to biologically inspired composites," Analytical and Bioanalytical Chemistry, vol. 381, no. 3, pp. 568-576, 2005.

[34] A. Tampieri, M. Sandri, E. Landi et al., "Design of graded biomimetic osteochondral composite scaffolds," Biomaterials, vol. 29, no. 26, pp. 3539-3546, 2008.

[35] E. Kon, M. Delcogliano, G. Filardo et al., "Orderly osteochondral regeneration in a sheep model using a novel nanocomposite multilayered biomaterial," Journal of Orthopaedic Research, vol. 28, no. 1, pp. 116-124, 2010.

[36] S. Scaglione, P. Giannoni, P. Bianchini et al., "Order versus disorder: in vivo bone formation within osteoconductive scaffolds," Scientific Reports, vol. 2, p. 274, 2012.

[37] C. Rey, M. Shimizu, B. Collins, and M. J. Glimcher, "Resolution-enhanced Fourier transform infrared spectroscopy study of the environment of phosphate ions in the early deposits of a solid phase of calciumphosphate in bone and enamel, and their evolution with age. I: investigations in the $v 4 \mathrm{PO}_{4}$ domain," Calcified Tissue International, vol. 46, no. 6, pp. 384-394, 1990.

[38] B. O. Fowler, E. C. Moreno, and W. E. Brown, "Infrared spectra of hydroxyapatite, octacalcium phosphate and pyrolysed octacalcium phosphate," Archives of Oral Biology, vol. 11 , no. 5, pp. 477-492, 1966.

[39] L. M. Miller, V. Vairavamurthy, M. R. Chance et al., "In situ analysis of mineral content and crystallinity in bone using infrared micro-spectroscopy of the $v 4 \mathrm{PO}_{4}^{-3}$ vibration," Biochimica et Biophysica Acta, vol. 1527, no. 1-2, pp. 11-19, 2001.

[40] M. Gelinsky, P. B. Welzel, P. Simon, A. Bernhardt, and U. König, "Porous three-dimensional scaffolds made of mineralised collagen: preparation and properties of a biomimetic nanocomposite material for tissue engineering of bone," Chemical Engineering Journal, vol. 137, no. 1, pp. 84-96, 2008.

[41] J. H. Bradt, M. Mertig, A. Teresiak, and W. Pompe, "Biomimetic mineralization of collagen by combined fibril assembly and calcium phosphate formation," Chemistry of Materials, vol. 11, no. 10, pp. 2694-2701, 1999.

[42] F. Nudelman, K. Pieterse, A. George et al., "The role of collagen in bone apatite formation in the presence of hydroxyapatite nucleation inhibitors," Nature Materials, vol. 9, no. 12, pp. 1004-1009, 2010. 

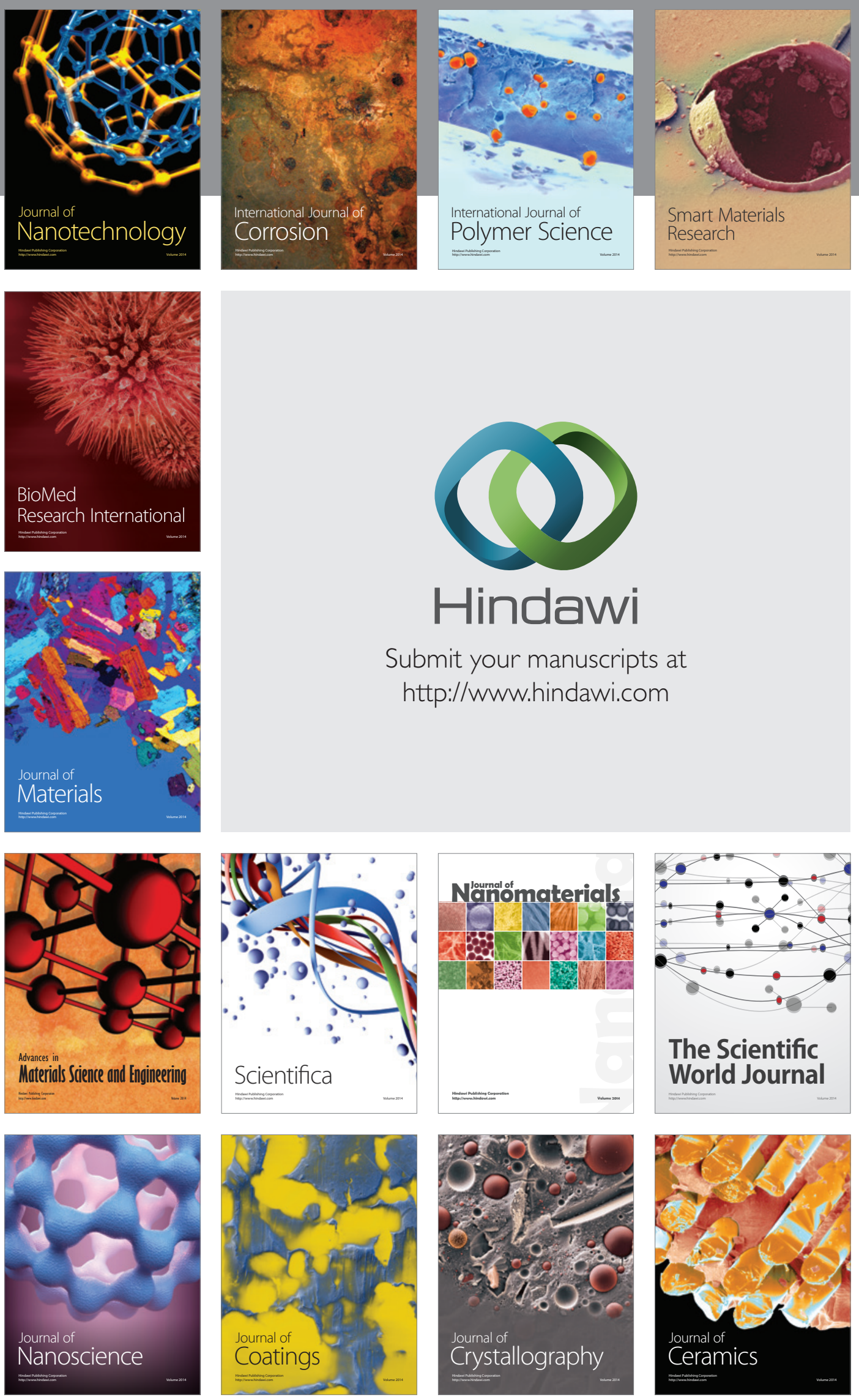

The Scientific World Journal

Submit your manuscripts at

http://www.hindawi.com

\section{World Journal}

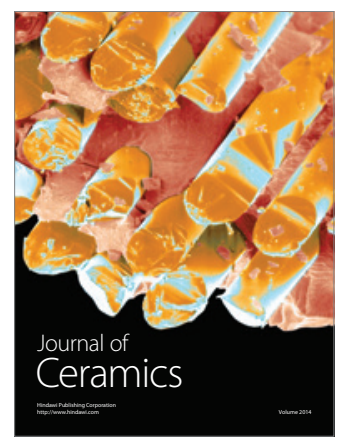

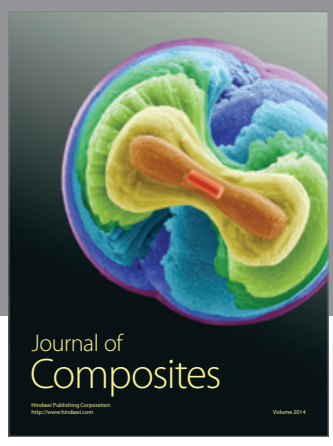
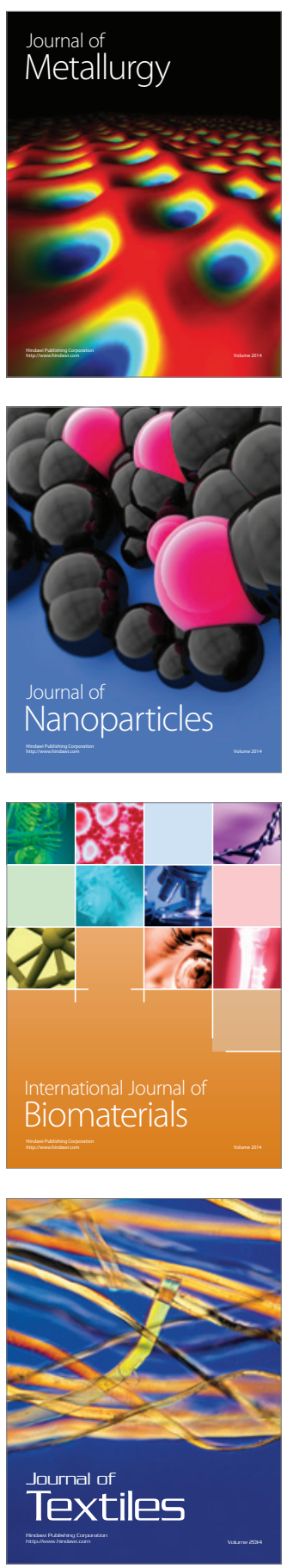